\title{
Sistema global del arte: museos de arte contemporáneo, bienales y ferias como mecanismos de posicionamiento urbano en los circuitos globales de intercambio
}

\author{
RODRIGO MILLÁN VALDÉS* \\ * Sociólogo Pontificia Universidad Católica de Chile - Magíster en Desarrollo Urbano PUC.
}

Una bienal no puede salvar una ciudad. Más bien, acompaña y refuerza simbólicamente un momento ascendente (...) El punto es que pensar una bienal es pensar un proyecto de desarrollo allí donde hay posibilidades de conducir la aceleración informativa y las transferencias del arte contemporáneo. (Justo Pastor Mellado: 2009)

\section{Resumen}

El presente ensayo tiene por objetivo indagar y analizar las estrategias de marketing urbano asociadas al sistema de promoción, difusión y comercialización de la producción artística contemporánea a nivel global, a través de tres de sus más reconocidas instituciones: Museos de Arte Contemporáneo, Bienales de Arte y Ferias de Arte. Mediante la presentación de algunos casos se busca explicitar los mecanismos de promoción de la competitividad urbana y de reforzamiento de la identidad localizada (city marketing, branding) a la luz de los conceptos de ciudad global y de circuitos globales, así como sus implicancias sobre la gestión del desarrollo de las áreas metropolitanas bajo el paradigma de la Planificación Urbana Estratégica (PUE) y la gobernanza (governance).

Se describirán los mecanismos de instalación y validación de estas instituciones, ya sean éstas impulsadas desde corporaciones público-privadas localizadas en ciudades específicas (tales como las Bienales de Venecia y Sao Paulo, Documenta en Kassel, la feria de ArtBasel, ParisPhoto o ArteBa) o iniciativas privadas (tales como Saatchi en Londres) que funcionan como galeristas, publicistas y mecenas de nuevos artistas y tendencias, que alimentan la proliferación de circuitos artísticos en red, los cuales son asumidos por los gobiernos locales, metropolitanos o nacionales como nuevo eje de acción económica y política.

* Correspondencia: rlmillanv@gmail.com 
La investigación se sostiene en la hipótesis de que las dinámicas de funcionamiento del sistema de difusión y comercialización de la producción artística contemporánea actúan trans-nacionalmente buscando posiciones privilegiadas en las jerarquías globales en términos económicos, políticos y culturales, al mismo tiempo que las autoridades metropolitanas buscan mejorar su posición relativa en los circuitos de intercambio internacionales, utilizando estos dispositivos tanto como fórmula de dinamización de la producción de las escenas locales, como de entrada a nuevos mercados potencialmente rentables.

\section{Procesos económicos globales}

Desde la segunda mitad del siglo XX, coincidente con el fin de la Segunda Guerra Mundial, en la sociedad occidental han venido gestándose cambios radicales en la organización del sistema económico y los términos de intercambio globales. La instauración del nuevo régimen de modernización capitalista, que era abierta con los acuerdos de Bretton Woods y la creación del Banco Mundial (WB) y el Fondo Monetario Internacional (IMF), trajo consigo modificaciones sustanciales al mercado financiero, las cuales vinieron a acentuarse luego, tras la crisis del petróleo de los años setenta y la emergencia de la nueva derecha impulsora del neoliberalismo económico (Barton: 2006), con la pérdida de preeminencia del capital industrial y el simultáneo predominio global progresivo del capital mercantil financiero de alta circulación. Es desde aquí que se sientan las bases para la circulación libre del capital financiero, la desregulación a las barreras arancelarias y la consiguiente apertura de mercados globales, la deslocalización de los procesos productivos a través de la externalización de servicios, la aparición de nuevas figuras empresariales y organizacionales tales como las alianzas estratégicas (joint ventures), las franquicias o la subcontratación de procesos y servicios, y la reorganización de los mercados de trabajo.

El proceso de fortalecimiento del sistema financiero global liderado desde el Hemisferio Norte, ocurrido desde mediados de la década de los setenta, se desarrolló a través de políticas de liberalización económica que facilitaron el desplazamiento de la inversión entre distintos mercados, mediante la incorporación de tecnologías de información y comunicación (TIC) que sirvieron para la consolidación de la acción en red, fortaleciendo así una trama global de ciudades transfronterizas (De Mattos, 2001).

Esta nueva organización de la economía, basada en los intercambios globales, ha producido una serie de modificaciones a la geografía del poder político, económico y cultural, trayendo consigo fenómenos que pueden ser considerados tanto localizaciones de lo global, como entidades nacionales que han sido desnacionalizadas (Sassen, 2007). Según Sassen, los procesos de globalización construyen entramados institucionales que se vuelven crecientemente complejos, en función a la amplia gama de interpretaciones y debates que suscita la puesta en práctica de procesos transnacionales en contextos urbanos particulares, así como el modo en que esas ciudades, así como los Estados-Nación, se adaptan y/o proponen nuevas condiciones (legislaciones específicas, condiciones de negociación, modelos de negocios, culturas de trabajo, etc.) a estas entidades globales. Tal como señalara Appadurai hace algunos años refiriéndose a la supuesta homogeneización cultural que vivía el mundo a comienzos de los noventa, el poder de las metrópolis para aclimatar, domesticar y nacionalizar a los diversos bienes culturales hacía 
difícil pensar que la heterogeneidad cultural de las distintas sociedades podría llegar a perderse por las condicionantes impuestas por el mercado (Appadurai, 2001, p. 44-45).

Bajo el paradigma de la acción en red, en un contexto de apertura global de mercados y de mayor velocidad de circulación de los capitales, las ciudades y regiones han tendido a tomar cada vez con mayor consideración dentro de su planificación las oportunidades y amenazas que potencialmente las vuelven más o menos competitivas (Begg, 1999). Los alcances y complejidades mayores de las decisiones han obligado progresivamente a los Estados-Nación a volver reflexivos sus procesos de decisión, abriendo un nuevo estilo de gobierno, distinto del modelo de control jerárquico y caracterizado por un mayor grado de cooperación y por la interacción entre el Estado y los actores no estatales al interior de redes decisionales mixtas entre lo público y lo privado (Sánchez, 2005). En estas características está contenida la noción de gobernanza, concepto que apela a los nuevos modos de coordinación y regulación provocados por la adaptación de lo local a lo global, así como a la formas de control y gestión adoptadas tras la transformación de las centralidades típicas del espacio fordista por actividades de producción y comercialización en espacios regionales intensamente policéntricos y reticulares (Klein y Fontan, 2005). La gobernanza, entendida en esos términos, viene a reemplazar a la planificación urbana normativa que predominó a lo largo del siglo XX por una acción pública estratégica, preocupada por estimular el rol del mercado y del capital privado en la configuración, desarrollo y gestión de lo urbano (De Mattos, 2002). Tal como afirma De Mattos, esta nueva dinámica de acción y coordinación incorpora la noción de plusvalía urbana a los criterios urbanísticos básicos.

Las transformaciones del sistema económico global no encontraron cabida solamente en el ámbito de lo nacional, sino que las ciudades adquirieron relevancia dentro de la planificación, en cuanto se las comenzó a reconocer como máquinas de producir riqueza (Fiori Arantes, 2000a, p. 14). Para afirmar esto, Fiori Arantes toma la idea de Peter Hall de la aparición de la ciudad-empresa, nacida desde las cenizas del consenso keynesiano, lo cual se ejemplifica con los proyectos de transformación del puerto de Baltimore y de los Docklands en Londres, durante el thatcherismo, en donde el modelo buscaba utilizar un volumen relativamente modesto de dinero público para generar -o, usando un verbo típicamente norteamericano, para leverage (hacer de palanca y mover) - una cantidad mucho mayor de capital privado (Hall, 1996, p. 368).

Si bien los procesos transnacionales se encuentran con realidades localizadas particulares que modifican su comportamiento prototípico -si es que esto existe-, la multiplicidad de lugares que son objeto de impactos económicos globales (inversiones extranjeras directas, instalación de empresas transnacionales, externalización de servicios, segmentación de mercados del trabajo, etc.) se encuentran en un sistema en el cual deben competir por la llegada de recursos e inversiones extranjeras. Los estándares de competitividad que imponen las fuerzas de mercado exigen que las autoridades y empresarios de las respectivas ciudades sean capaces de aplicar estrategias de oferta de espacio (Klein y Fontan, 2005). A través de ellas se busca entregar incentivos a la localización de parte de los procesos productivos, el acuerdo entre inversores extranjeros y empresas nacionales para la prestación de servicios, la posibilidad de negociaciones e intercambios económicos privilegiados, etc. Es así como se ha masificado dentro de la gestión urbana la fórmula mágica de los grandes eventos, con sus megaproyectos, para atraer turistas e inversionistas hacia sus respectivas ciudades (Fiori Arantes, 2000a, p. 12). 
Para poder ser capaces de ofrecer esta serie de posibilidades y servicios, las ciudades deben convertirse en competitivas a partir de la incorporación de una gama de atributos valorados por el mercado internacional de capitales: marco legal y político estable -reglas del juego-, estabilidad económica, facilidad para hacer negocios, posibilidad de circulación de capitales, centros de negocios consolidados, disponibilidad de información, capital humano avanzado, calidad de vida para ejecutivos, etc. (MCWW, 2008, p. 4). La frenética búsqueda por aparecer en los mejores puestos posibles dentro de los rankings de competitividad urbana da cuenta de la tenencia de estos atributos, tras lo que algunos autores llaman una espesura cualitativa que habia perdido (la ciudad) frente al esquematismo de la ciudad global (Sabaté y Tironi, 2008, p. 9).

Además de garantizar la puesta en práctica de estos requisitos, para cierto tipo de inversiones y conocimientos asociados a ellas, las ciudades deben ser capaces de proyectar una imagen (así como una marca) que avale esos criterios; las aspiraciones, visiones e imágenes de globalidad, diversidad y sofisticación, capaces de encantar al exterior (Vanolo, 2008), son muchas veces buscadas por las campañas nacionales o metropolitanas, las cuales además acentúan la coordinación entre los sectores públicos y privados y su acción coordinada en torno a la promoción del desarrollo (Pagano y Bowman, 1997, p. 50-51). Como afirma Fiori Arantes a propósito del Efecto-Guggenheim o Efecto-Gehry en Bilbao, lo que se pone a la vista es el propio emblema de credibilidad, las señales emitidas por un consumado ejemplar de manierismo arquitectónico: materiales ostensiblemente calculados para ofuscar por el brillo "high-tech"; atmósfera de vanguardia sugerida por los volumenes de corte deconstruccionista; ambiente introvertido de enclave para los "happy few". Un ícono, en fin, del mundo de los integrados, en este caso la indispensable ventana de los altos servicios culturales abriéndose hacia el sector terciario avanzado, sin el cual la mencionada voluntad elegantemente arribista de inserción no pasaría de un ruego piadoso (Fiori Arantes, 2000b).

Los procesos económicos globales, entendidos como creciente especialización y diferenciación funcional interregional, producen en los distintos agentes pertenecientes a los sistemas políticos y económicos la adopción de estrategias cada vez más desarrolladas de creación de una identidad particular como ciudad o región. El marketing urbano ha resurgido con fuerza durante los últimos años -vale recordar que por lo menos desde fines del siglo XIX han existido estrategias de posicionamiento global de ciudades tales como las Exposiciones Internacionales, los Juegos Olímpicos o las Ferias Científicas Mundiales-, vehiculizando una serie de diferentes tipos de imágenes, cada una de ellas basada en un campo semántico diferente (Benko, 2000). Según Benko, han existido apelaciones a representaciones artísticas-estéticas transmitidas mediante las creaciones artísticas; representaciones mediáticas transmitidas cotidianamente a través de los mass-media; representaciones elaboradas desde la ciencia y la reflexión crítica que buscan racionalizar la imagen del espacio estudiado; representaciones construidas desde los discursos políticos; y representaciones espontáneas y cotidianas, construidas como en la acción de los habitantes de la determinada ciudad o región -espacio vivido-.

Dentro de este esquema de distintas tipologías, los museos de arte contemporáneo, así como las bienales y ferias de arte, funcionan trabajando la síntesis de las distintas representaciones. Por un lado, generalmente utilizan dentro de sus estrategias de promoción la creación de una gran obra arquitectónica, sea esta permanente o transitoria, que sirva como ícono urbano y centro 
de acción artística y cultural. Por otra parte, catalizan voluntades políticas y económicas de las autoridades y poderes económicos metropolitanos, regionales y nacionales que buscan en esta instancia la oportunidad de validar tanto sus políticas culturales, como la apertura potencial a nuevas posibilidades de inversión y rentabilidad. Además, mediante estas intervenciones urbanas, las autoridades buscan revalidar su legitimidad democrática -mediante la acción misma de entregar cultura a la ciudadanía bajo la fórmula de la redistribución del lujo (Esteban, 2007, p. 45)-, gatillar procesos económicos urbanos asociados a estos polos de desarrollo, y promover la llegada de cierto tipo de actividades económicas, bienes y personas asociadas a lo que Richard Florida llama el núcleo súper creativo -alta tecnología y matemáticas, arquitectura e ingeniería, ciencias (biológicas, físicas y sociales), educación, arte y diseño, entretenimiento, medios de comunicación- (Florida, 2002, p. 328, citado en Sabaté y Tironi, 2008).

Tal como advierten algunos autores, en los últimos veinticinco años las administraciones locales y regionales han implementado, dentro de sus planes de desarrollo, la promoción de proyectos urbanos de alto impacto. Como señalan Sánchez y Bienenstein a propósito del Camino Niemeyer en Niteroi y el Museo Guggenheim en Río de Janeiro, en la búsqueda por inversiones que permitan impulsar su desarrollo, las administraciones municipales han intentado asociar sus iniciativas a los llamados "proyectos estratégicos", cuya implementación está apoyada en el discurso de reversión de la crisis urbana y de las ventajas en competitividad interurbana que estos proyectos puedan promover (Sánchez y Bienenstein, 2005). Estas estrategias de desarrollo se sostienen en la premisa de que es posible gestionar y reestructurar los espacios urbano-metropolitanos bajo esquemas económicos neoliberales, a través de la incorporación de megaproyectos -y el respectivo marketing urbano asociados a ellos- capaces de gatillar fuertes aumentos en el capital de las economías locales, tanto a través de la industria turística como de la llegada de nuevas inversiones (p. 226-227). Esta forma de articulación de intereses económicos y políticos ha sido criticada en cuanto instrumentaliza al ámbito de la cultura, banalizándola y convirtiéndola en mero símbolo de innovación de las ciudades (Esteban, 2007). Tal como advierte Ińaki Esteban, en una sociedad de la abundancia, el ornamento se ve como normal y hasta necesario, de modo que lo sobrante ocupa un lugar politico y económico fundamental en el diseño de estrategias y en la redacción de informes (p. 18).

En esta lógica, la promoción del arte contemporáneo ha sido una de las imágenes que más ha intentado ser promovida transversalmente por las ciudades del mundo occidental, en un intento por demostrar intereses que van más allá de la mera sobrevivencia y reproducción de la sociedad, así como por integrarse a una red de negocios que globalmente mueve grandes flujos de capital. Integrarse a ella trae consigo una serie de valoraciones asignadas en torno a su imagen internacional y su poder relativo dentro del marco transnacional. Las ciudades pueden ser entendidas como plataformas de desarrollo de estéticas particulares (Giannetti, 2001, p. 165), a través de las cuales las autoridades pueden buscar proyectar determinado mensaje, el cual puede entrar o no en contradicción y disputa con el de otros agentes que sostienen determinadas agendas.

Lo relevante es comprender la posibilidad que abre el arte, como sistema en su conjunto, de posicionar mensajes orientados directa o indirectamente al establecimiento de grandes negocios en torno a la producción, difusión y comercialización de las mismas obras, así 
como de la posibilidad de dinamizar una amplia serie de economías asociadas a la creación, permanencia y consolidación de una escena artística. A continuación se revisarán algunos de estos mecanismos.

\section{Sistema Global del Arte Contemporáneo Institucionalizado: Museos, Ferias y Bienales}

\subsection{Museos de Arte Contemporáneo}

El arte contemporáneo ha logrado, en algunos lugares del planeta, convertirse en un proyecto económico que traspasa la comercialización de las obras, basado en la potencial generación de núcleos turísticos, la activación de economías relacionadas -industrias turísticas y del entretenimiento, coleccionismo y galerismo local, industria editorial-, el desarrollo de distritos culturales y de procesos de regeneración urbana, etc. Las posibilidades de aumentar los puestos de empleo y la obtención de riqueza hacen que este modelo se haya vuelto atractivo para las autoridades de distintos puntos del planeta, a diversas escalas territoriales -iniciativas metropolitanas, regionales e incluso nacionales confluyen en el diseño y gestión de estos proyectos-. Este proceso se encuentra íntimamente ligado al aumento del atractivo de los museos a través de nuevas formas de organización de sus contenidos, con las cuales la distinción entre colección permanente y exhibiciones temporales ha perdido validez, en cuanto las colecciones son constantemente reorganizadas temporalmente y las exposiciones temporales se han transformado en grandes colecciones permanentes en circulación (Huyssen, 2002).

Análogo a las exposiciones internacionales ocurridas en distintas ciudades de Occidente desde mediados del siglo XIX, tales como las de Londres en 1851 o Chicago en 1893 -en las que se llevaron a cabo grandes obras, cuyo fin era el de impactar a los participantes del mundo entero, tales como el Palacio de Cristal o los parques y avenidas planificados por Olmsted respectivamente-, hoy en día uno de los dispositivos más utilizados en diversas ciudades es la creación de Museos de Arte Contemporáneo, los cuales buscan instalarse como referencias urbanas capaces de detonar flujos de inversión directa sobre la ciudad, apoyar la creación de nuevos puestos de empleo, dinamizar áreas deprimidas de la ciudad dotándolas de intensidad de uso, etc. Asimismo, los museos a través de sus diagramas programáticos-colecciones, exposiciones transitorias o sus actividades de extensión- buscan incluir una amplia gama de obras de artistas provenientes de distintos lugares del mundo, garantizando así el carácter global de su discurso. Muchas veces el dotar de una imagen transnacional a algún área de la ciudad se constituye en la estrategia de construcción de imagen urbana, a través de la cual se busca seducir al potencial visitante (Smyth, 1994, p. 2-3). Conseguir una insignia o hito reconocible por el mundo entero es un viejo anhelo dentro de la planificación urbana: constituirse en global y universal es buscado por muchas ciudades que pretenden distinguirse como únicas en el concierto mundial. Una de las posibilidades que ofrece hoy la escena global -evidentemente a quienes pueden pagarlo- es a través de un museo.

Si hay un caso paradigmático, éste es el del Museo Guggenheim de Bilbao, proyectado por el conocido arquitecto estadounidense Frank Gehry e inaugurado el año 1997. Desde mediados de la década de los setenta la desindustrialización, así como la restructuración y reorganización de los procesos productivos, trajo consigo un declive de la actividad económica, alzas en 
los índices de desempleo y pobreza, así como la obsolescencia física y ambiental de extensos paños urbanos ubicados sobre el borde del río (Rogers y Power, 2000; Rodríguez y Martínez, 2003). La reactivación económica de otras ciudades españolas desde mediados de los ochentas, tales como Sevilla o Madrid, no tuvo impacto sobre Bilbao, que carecía de estrategias que revirtiesen la tendencia hacia el fracaso urbano, en términos de riqueza y flujos de capital. Sin embargo, a mediados de los noventa las autoridades metropolitanas impulsaron un plan estratégico de revitalización urbana, mediante el cual buscaron detonar, a través de una serie de intervenciones a distinta escala, procesos de regeneración de las economías de la ciudad. Así, se decidió invertir en accesibilidad y transporte, así como en regeneración del entorno urbano y ambiental, en el desarrollo de proyectos urbanos que dinamizasen las áreas deterioradas y que apoyasen la vocación cultural e innovadora de la ciudad (Rodríguez y Martínez, p. 187). Es dentro de este marco que nace Guggenheim Bilbao.

Bastante se ha discutido acerca del alcance dinamizador que ha tenido para la ciudad la instalación de un museo que, en principio, pudo haber estado en cualquier otra ciudad vasca, española, europea u occidental, pero que, al estar donde está, ha sido capaz de colocar a Bilbao en la red de cierto tipo de destinos turísticos, asociados a las grandes obras de arquitectura y a la posibilidad de observar nuevas propuestas conceptuales de arte. Si bien existen una serie de debates en torno a la constitución de ciudades-museo y de parques temáticos -que en este caso sería en torno a la idea de la vanguardia contemporánea-, lo que aquí interesa es entender cómo las ciudades entran en la lógica de las industrias culturales (Montaner, 2003), mediante la incorporación de grandes hitos a la composición urbana. El director general de Guggenheim Bilbao, Juan Ignacio Vidarte, señala: El efecto Guggenheim es una inversión en una infraestructura cultural que sirve de catalizador a todo un proceso de transformación de la ciudad (...) Otro de los efectos más intangibles ha sido la proyección de la imagen de la ciudad en el exterior e incluso la psicología de la ciudad, esa transformación que hace que los ciudadanos se sientan con una confianza recuperada y por lo tanto en mejores condiciones de abordar los proyectos de futuro ${ }^{1}$. El intento por dotar a Bilbao de un status global se condice con una serie de indicadores que reafirman este hecho: según la revista Forbes, en el año 2001, sólo cuatro años después de su inauguración, el museo tuvo cerca de un millón de visitantes, de los cuales el $82 \%$ de ellos declaró haber visitado la ciudad o haber extendido su visita sólo por la existencia del Guggenheim. Este solo lugar logró dinamizar a una serie de economías asociadas locales en un monto cercano a los 170 millones de euros².

El efecto Guggenheim se ha intentado replicar en una serie de ciudades, con diversos resultados en su efectividad: la Casa de la Música de Koolhaas en Porto, las incipientes negociaciones para instalar una sede del Centro Pompidou parisino en Shanghai, las controversiales obras del complejo de la Ciudad de las Artes y las Ciencias de Calatrava en Valencia, y el desenfrenado esfuerzo de los Emiratos Árabes, a través de Abu Dhabi, de posicionarse en el concierto global como el gran núcleo cultural y cosmopolita de Medio Oriente. En la mayoría de estos

1 Disponible en http://news.bbc.co.uk/hi/spanish/misc/newsid_6514000/6514271.stm

2 Disponible en http://www.forbes.com/2002/02/20/0220conn.html 
casos se buscan marcas arquitectónicas que apoyen y refuercen la construcción de ornamentos urbanos (Esteban, p. 44).

Vale la pena detenerse en este último caso, por la complejidad de las redes que ha trazado, así como por lo ambicioso de los proyectos que ha intentado desarrollar. Los Emiratos Árabes han buscado, a través de las más extravagantes inversiones, generar un punto de alto atractivo turístico que, como estrategia de diversificación de los ingresos, logre complementar a la industria petrolera. Más allá de la Isla Palmera o el hotel Burj Al Arab de Dubai, Abu Dhabi, el principal de los Emiratos, ha apuntado a convertirse en el centro cultural de Medio Oriente a través de acuerdos con algunas de las grandes instituciones culturales de Occidente, tales como el Museo del Louvre y la Universidad de La Sorbonne francesa. Las tratativas y negociaciones para llevar a cabo los acuerdos fueron tratadas a nivel de Estados -durante el gobierno de Jacques Chirac-, bajo la idea de que las políticas culturales, así como la potencial apertura de grandes nuevos mercados y negocios, debían ser gatilladas desde la iniciativa pública. El Louvre, la gran exportación cultural europea, sirve como puente de entrada para potenciales negocios asociados a la industria cultural, así como a ámbitos no relacionados al sistema que puedan utilizar las redes de confianza ya establecidas. Porque a fin de cuentas, tal como declara Sassen, el aumento de movilidad de capital provoca nuevas formas de concentración locacional (Sassen, 1999, p. 60), al mismo tiempo que la presión por volverse competitivo obliga a la internacionalización (Gordon, p. 1001), tanto de parte de quien exporta el bien cultural -que pasa a ocupar una posición hegemónica dentro del esquema del poder global-como de quien lo importa, que se inserta en los circuitos globales especializados del arte contemporáneo. En Abu Dhabi han entendido esto, y han acelerado los procesos de importación de bienes culturales, mediante diversas iniciativas, tales como el proyecto del nuevo museo Guggenheim -que increíblemente intenta reproducir el efecto Bilbao contratando al mismo Frank Ghery- y del Centro de Artes Escénicas de Zaha Hadid, quien pertenece, al igual que Ghery, a la primera línea del sistema de arquitectos globales.

La competitividad de las ciudades, en muchos de estos casos, queda remitida a la posibilidad de desarrollar una gran obra arquitectónica, ojalá acompañada del patrocinio de un ícono de las industrias culturales, que sea capaz de movilizar una serie de recursos e inversiones que garanticen posteriormente flujos de capital lo suficientemente significativos como para posicionar a la ciudad dentro del circuito global o regional. El caso de las bienales de arte también ilustra este fenómeno y enriquece la discusión acerca de los modelos de financiamiento y gestión de las iniciativas de marketing y competitividad urbana.

\subsection{Bienales de Arte}

Las bienales de arte, entendidas como una institución al interior del sistema del arte (Chiuminatto, 2009, p. 14), han tenido históricamente la función de abrir espacios de discusión pública acerca del sentido del arte en las sociedades que las acogen. Sin embargo, estas instituciones no pueden abstraerse de las distintas complejidades del sistema económico global relativas al financiamiento y a la competitividad urbana. De hecho, tal como critican algunos artistas y curadores, la dependencia del arte a variables económicas ha hecho que los criterios curatoriales, los participantes y los formatos de las obras en ocasiones queden remitidos a lo que asegure 
mayores posibilidades de difusión y comercialización; llegando incluso a señalar que las bienales fomentan un saber que instrumentaliza el arte, al exigirle que entregue a la comunidad resultados prácticos e inmediatos (Marín, 2009, p. 31).

Las bienales hoy en día surgen como resultado de acuerdos entre las políticas culturales, tanto del Estado (a pesar de ser actividades que están circunscritas geográficamente por la escala urbana) como de los gobiernos metropolitanos, con la empresa privada, en función de la construcción de una plataforma de inversiones simbólicas (Mellado, 2005), lo cual es manifestación de lo que Harvey denominó hace veinte años como empresarialismo de la gestión urbana (Harvey, 1989). Las bienales, siguiendo este análisis, son una de las formas exploradas por los gobiernos nacionales, regionales y metropolitanos para incorporar nuevas líneas de acción capaces de establecer vínculos con la empresa privada, potenciar a pequeñas firmas -en este caso a la escena artística local-y promover a algunas áreas de la ciudad que sirvan como plataforma de negocios capaces de llevar oportunidades de bienestar a una proporción de los habitantes de la ciudad. El modelo de gestión de estas entidades culturales es institucionalizado a través de fundaciones que representan los intereses en cuestión, lo cual queda demostrado al indagar en el entramado de la Fundación Bienal de Venecia, la cual está compuesta por miembros del Concejo de la Ciudad, del Ministerio de Cultura Italiano e inversores privados. Esta distribución de poderes se ve reforzada por los modelos de financiamiento a los que aspiran lograr como entidad cultural: que un $30 \%$ de los ingresos provenga de patrocinadores privados, un $30 \%$ de ingresos propios, un 30\% de transferencias del sector público y un $10 \%$ de las utilidades a generar mediante la ampliación de las actividades de la propia bienal ${ }^{3}$.

Es en la búsqueda de criterios de distinción de la ciudad respecto a otras en donde se juega la competitividad: tal como señala Gordon, en el creciente reconocimiento de que la geografía importa para lograr alcanzar los objetivos económicos trazados, es que las autoridades deciden potenciar las ciudades como centros especializados en actividades relacionadas con sus regiones (Gordon, p. 1002). Lo interesante de preguntarse es, entonces, ¿qué hace atractiva a una bienal de cierta ciudad a la vista del circuito global del arte? A primera vista la respuesta es que es el programa o la curatoría de una bienal lo que le da sentido y la hace atractiva como fenómeno global. Si bien esto es cierto, también lo es que, desde una clave post-colonial del análisis de negocio, estas instancias sirven como espacio de provisión de nuevas obras y claves interpretativas (materias primas en palabras de Chiuminatto) que enlacen una escena artística local o regional con el mercado global del arte, a través de galeristas, coleccionistas privados o institucionales o subastas. La conexión entre lo local y lo global en este sistema funciona de forma análoga a las categorías de la Nueva Economía propuestas por Castells: la información es clave en cuanto define qué tendencias y artistas son potenciales superventas, construyendo apetitos y pretensiones globales que se masifican a través de los medios de comunicación interactivos, segmentando así entre nodos centrales dentro del sistema artístico global y escenas periféricas satélites que intentan adecuarse, en la medida de lo posible, a las corrientes principales (Castells, 2000).

3 Disponible en http://www.labiennale.org/en/biennale/foundation/ 
Uno de los casos más interesantes de posicionamiento y marketing urbano a través del sistema artístico global en América Latina es el de Porto Alegre, Brasil; desde mediados de la década de los noventa que la clase política y empresarial gaúcha ha intentado proyectarse, a partir de la plataforma del Mercado Común del Sur (MERCOSUR), y representar su poder a escala regional como contrapeso al predominio económico, político y simbólico de Sao Paulo, como nodo central en la red global. Para llevar a cabo estos propósitos se ideó la Bienal del MERCOSUR, la cual fue pensada como mecanismo de resolución de la compleja necesidad simbólica que posee un grupo humano determinado, acerca de la dimensión imaginaria de su representación del poder (Mellado, 2005). Para esto, las autoridades estaduales coordinaron la creación de una fundación público-privada que gestase la constitución de la primera bienal. Coordinar inversiones privadas cuya rentabilidad estuviese garantizada a través de especiales campañas de marketing y de visibilización de las marcas patrocinantes, reactivar y redescubrir zonas deprimidas de la ciudad en las cuales se llevase a cabo la puesta en escena de las obras, instalaciones y performances, y consolidar una red de financiamiento e inversión de actividades continuas en los dos años entre bienal y bienal, se plantearon como macro-objetivos para la puesta en marcha de la actividad. Además, tal como seńala Mellado, la Bienal en Porto Alegre buscó constituirse en contrapeso a la mítica sobredimensión del eje Sao Paulo-Río (Mellado, 2005), convirtiendo así a la bienal en un dispositivo de reparación política y, por añadidura, económica. Esta búsqueda de reconocimiento de parte de las clases dirigentes gaúchas, fue reforzado además por la construcción del nuevo edificio de la Fundación Iberé Camargo, a cargo del arquitecto portugués Álvaro Siza, que dotó a Porto Alegre de la obra de un arquitecto de primer orden dentro del reconocimiento de la crítica internacional especializada, pudiendo así proyectar la imagen de una ciudad cosmopolita, contemporánea, dispuesta a invertir en valor agregado, etc. A través de estos dos mecanismos de validación, el gobierno federal de Río Grande do Sul, la prefectura de Porto Alegre y las empresas privadas localizadas en la región lograron establecer nuevos ejes temáticos lo suficientemente competitivos como para lograr llamar la atención del sistema artístico iberoamericano. De esta forma, siguiendo los conceptos de Bourdieu relativos al campo de producción cultural, lo que las élites políticas y económicas gaúchas han venido intentando durante los últimos quince años ha sido una redefinición de su posición en el sistema artístico y económico global, mediante cambios en las relaciones de poder (Bourdieu, 1993). A través de esta redefinición se ha buscado obtener un posicionamiento favorable en el orden global, tanto como centro de producción, reflexión, difusión y comercialización de las obras de arte, como de espacio de desarrollo de una diversidad de industrias dinámicas asociadas al sistema artístico, tales como el turismo y el entretenimiento, la banca y las aseguradoras privadas, o las empresas de transporte y telecomunicaciones.

\subsection{Ferias de Arte}

Como el espacio por excelencia de la comercialización, las ferias de arte han logrado legitimarse al interior del sistema como aquella instancia en donde galerías, representantes, artistas, conferencistas, editoriales y un sinnúmero de actividades satélites acuden a participar del intercambio y la especulación en torno a las obras de arte. Art Basel, la gran feria de arte del mundo, logró este año convocar a cerca de 300 galerías de distintos continentes y escenas artísticas, representando a cerca de 2500 artistas. Los impactos sobre la ciudad son evidentes: en el año 2008, durante los cinco días de duración de la muestra, asistieron cerca de 60.000 
visitantes ${ }^{4}$, lo que impacta de sobremanera en la industria turística en un área metropolitana de 700.000 habitantes.

Entendiendo el impacto global en términos de flujos globales de intercambio que puede traer un evento como éste, la transnacional suiza de manejo de inversiones UBS junto a la aseguradora AXA decidieron auspiciar una nueva versión de esta feria en una nueva localización en el mundo. ¿Dónde y cómo elegir? El nuevo lugar debe ofrecer una serie de atributos: mercado y demanda potencial amplia, localización privilegiada en términos de oferta de bienes de arte, oferta hotelera, seguridad financiera (transacciones, tributaria, etc.), escena artística y cultural consolidada o en vías de consolidación, etc. En definitiva, apostar a un lugar nuevo, no consolidado en la escena global del arte, pero que cuente con los atributos suficientes como para minimizar los riesgos. ¿¿Resultado? Realizar la versión de Art Basel en Miami Beach, cuyas características hacen viable y atractiva la realización de la feria: escena cultural e industria del entretenimiento consolidadas, inversores privados norteamericanos con alto poder adquisitivo, puerta de entrada al mercado latinoamericano -tanto de artistas y galeristas, como de potenciales compradores-, existencia de infraestructura de convenciones para el desarrollo de una serie de actividades paralelas, etc.

El potencial de Miami como marca global puede ser rentabilizado y potenciado a través de una feria de arte como Art Basel, la cual trae beneficios económicos tanto a los patrocinantes como al área metropolitana de Miami; fruto de estrategias de marketing y posicionamiento global de la ciudad, la escena del arte contemporáneo de Miami es hoy en día menos dependiente de la escena neoyorkina, tal como señalan algunos galeristas locales ${ }^{5}$, así como indirectamente ha logrado ganar terreno en el mercado latinoamericano sobre otras escenas, tal como la feria de ARCO Madrid.

Así como Miami supo rentabilizar su posición geográfica, se están dando hoy en día otro tipo de emprendimientos en el mercado internacional del arte, que están modificando algunas de las dinámicas de producción, difusión y comercialización. Quizás, la más interesante como fenómeno global es la venta de arte online que institucionalizó ya la galería londinense Saatchi. La decisión de ofrecer arte online, sin el pago de comisiones de intermediarios, dentro de un sistema en que es posible que artistas de cualquier lugar del mundo se inscriban y suban registros de sus obras, crea un nuevo modelo de negocios a través del cual el gran ganador es Saatchi como marca. Más allá de todas las polémicas en torno a la precarización de las obras de arte en el proceso de adecuación al espacio virtual de negociación, lo que aquí ocurre es que la galería recibe en tiempo real los gustos y preferencias de sus potenciales compradores, tomándole el pulso al mercado, logrando así adecuar la oferta de la galería física pre-existente y recopilando obras que serán luego éxito garantizado en el fluctuante mercado del arte contemporáneo.

4 Disponible en http://www.artbasel.com/go/id/ss/

5 Disponible en http://www.theblowup.com/06/Projects/art_basel/ 


\section{Discusión}

El fenómeno recién mencionado tensiona la creencia en la dependencia absoluta del sistema global de arte contemporáneo respecto del lugar, en cuanto deslocaliza sus procedimientos de promoción, exhibición y comercialización. Sin embargo, sostener que esta será la tendencia imperante es pasar por alto que el funcionamiento del sistema depende de la articulación de distintos ejes de acción, muchos de los cuales se sostienen en los atributos de localización de sus instituciones, así como que el arte contemporáneo alimenta la renovación y actualización de otros ámbitos de la vida social, como la economía global o la gobernabilidad local.

Tanto los museos de arte, como las bienales y las ferias cumplen un rol específico dentro del sistema, los cuales, si bien están orientados a dinamizar las escenas artísticas locales y regionales, son desarrollados de forma distinta. Por un lado los museos de arte contemporáneo buscan reactualizar constantemente su oferta programática y atraer tanto a nuevos visitantes como inversores, mediante la reactualización de sus colecciones permanentes y la exposición de colecciones temporales, capaces de construirse públicamente cada vez con más espectacularidad. En lo que algunos autores llaman la construcción de los espacios turísticos enclávicos, se busca regular el deseo, el consumo, los movimientos y el tiempo (Judd, 2003), mediante los cuales asegurar la rentabilidad en los balances financieros, mantener encantadas a las audiencias y promover la llegada de nuevos visitantes, así como reforzar la consolidación de distritos o barrios culturales dentro de la ciudad. Además, la proliferación de este tipo de instituciones alrededor del mundo da cuenta del viejo anhelo de los países en vías al desarrollo de adquirir símbolos de civilidad, modernidad y contemporaneidad mediante la incorporación a la red de producción de conocimientos estéticos.

Las bienales por su parte, buscan animar y consolidar procesos ascendentes al interior de escenas artísticas locales y regionales, con el fin de abrir nuevos espacios de reflexión y producción artística asociada a nuevas interrogantes, a través de las cuales retroalimentar al sistema en su conjunto. La virtud de la bienal está en que, al estar programada como una actividad de carácter urbano circunscrita por límites específicos de tiempo, puede facilitar las estrategias de promoción de la misma, logrando cautivar potenciales visitantes que posibiliten el logro de números azules para las empresas y gobiernos locales, regionales y nacionales que están patrocinándolas.

Por último, las ferias de arte intentan maximizar sus atributos de localización en pos de rentabilizar su posición relativa respecto a escenas de producción (artistas) y de comercialización (galeristas, coleccionistas, casas de subastas). Muchas veces sin criterios curatoriales claros, o al menos cuestionables en cuanto a la coherencia de las propuestas que conviven en su interior, las ferias de arte, como un mercado, buscan ligar vendedores y compradores de distintos lugares del mundo que se encuentran aquí para llevar a cabo una transacción. Normalmente, tanto las autoridades de la ciudad como los promotores han intentado rentabilizar esta oportunidad, generando una serie de servicios y actividades que orbiten en torno a la feria, ofreciendo servicios complementarios y/o alternativos a las actividades que se lleven a cabo al interior de ella. 
Dentro del esquema recién presentado, en torno al sistema global del arte contemporáneo y sus instituciones más representativas, vale preguntarse si esta tendencia no es discutida por algunos actores pertenecientes a las escenas artísticas locales; la presencia de escenas de contracultura frente a la institucionalidad del arte global está desarrollándose fuertemente, por lo menos como discurso en una serie de escenas territorializadas (Bravo, 2009). Y es, tal vez, más radical el discurso allí donde el mercado global se ha instalado con fuerza, tal como es el caso del situacionismo y las performances sobre la ciudad presentes en la escena paulista -vale recordar las amplias repercusiones que tuvo dentro del debate artístico latinoamericano la decisión curatorial de Ivo Mesquita en la 28 Bienal de Sao Paulo de reducir al mínimo las obras en exhibición, y las respuestas de los colectivos artísticos paulistas a esta opción-, o el espíritu artístico independiente de Berlín. Sin embargo, lo interesante es ver que estos movimientos funcionan muchas veces en paralelo a los mismos circuitos, replicando algunas de sus dinámicas, pero sin la pretensión exacerbada del lucro -por lo menos como bandera de discurso- ya instalada en el interior del mainstream.

Tal como ocurre en torno a la aparición de grupos anti-sistémicos en paralelo a los grandes foros económicos mundiales, es común que simultáneamente a la realización de bienales y ferias de arte ocurran eventos “independientes” que, aprovechando las economías de escalas, así como el clima de discusión y apreciación artística predominante, instalen espacios de promoción y difusión de pensamientos y producciones críticas. La creación de estos espacios obedece a estrategias globales de posicionamiento de discursos y propuestas artísticas que, en la medida en que adquieren visibilidad, son integradas al mercado global del arte, a través de, por ejemplo, el espacio museográfico, bajo la forma de exposiciones relacionadas a nuevas escenas o a miradas retrospectivas sobre la producción de tal o cual país o ciudad. Lo sugestivo, como fenómeno urbano, es que estos eventos alternativos, como cuarto elemento reconocible al interior del sistema global del arte contemporáneo, son capaces de articular circuitos paralelos, los cuales, motivados más por pretensiones estéticas y políticas que económicas, funcionan como contrapeso conceptual al circuito global institucionalizado.

El funcionamiento de los circuitos globales del arte contemporáneo debe seguir siendo estudiado, en la medida que, más allá de las implicancias que tiene como fenómeno estético y político, es capaz de articular funcionamientos en red, así como procesos de inversión y regeneración urbana en torno a la construcción de imágenes y visiones de ciudad global. Siguiendo a Sassen, hay que investigar la dinámica globalizadora en el interior del espesor institucional y social de lo nacional, donde se mezclan elementos nacionales y no nacionales (Sassen, 2007, p. 13), con el objetivo de lograr comprender de mejor forma la relación de lo global y lo local manifiesta en los distintos ámbitos de la vida colectiva, con todas las dificultades que ello trae consigo en términos de gestión territorial y coordinación entre los distintos agentes que se ubican en la órbita de influencia de las respectivas ciudades. 


\section{Referencias bibliográficas}

Appadurai, A. (2001). La modernidad desbordada. Buenos Aires: Fondo de Cultura Económica.

Barton, J. (2006). Sustentabilidad urbana como planificación estratégica. Revista EURE (96) pp. 27-45.

Begg, I. (1999). Cities and competitiveness. Urban Studies (36: 5-6) pp. 795-809.

Benko, G.(2000). Estrategias de comunicación y marketing urbano. Revista EURE (79) pp. 67-76.

Bourdieu, P. (1993). The field of cultural production. Columbia: University Press.

Bravo, V. (2009). ¿Cómo se ve la contracultura chilena desde la institucionalidad? En http://www. wokitoki.org/wk/219/como-se-ve-la-contracultura-chilena-desde-la-institucionalidad.

Castells, M. (2000). Materials for an exploratory theory of the network society. British Journal of Sociology (51:1) pp. 5-24.

Chiuminatto, P. (2009). Bienal internacional: categoría estética y económica. Cuadernos de la Escuela de Arte UC (14), pp. 14-21.

De Mattos, C. (2001). Metropolización y suburbanización. Revista EURE (80) pp. 5-8.

De Mattos, C. (2002). Transformación de las ciudades latinoamericanas: ¿impactos de la globalización? Revista EURE (85) pp. 5-10.

Esteban, I. (2007). El efecto Guggenheim. Del espacio basura al ornamento. Barcelona: Anagrama.

FioriArantes, O. (2000a). Cultura y coaliciones de poder y dinero en las nuevas gestiones urbanas. BLOCK (5) pp. 12-21.

FioriArantes, O. (2000b). Pasen y vean... Imagen y city-marketing en las nuevas estrategias urbanas. Punto de Vista (66) pp. 16-19.

Florida, R. (2008). Who's your city? Canada: Random House Canada.

Giannetti, C. (2001). ArsTelematica: The Aesthetics of Intercommunication. En P. Weibel \& T. Druckrey (Eds.). Net Condition: artand global media. Steirischer Herbst, Graz. Cambridge, Mass: MIT Press.

Gordon, I. (1999). Internationalisation and urban competition. Urban Studies (36: 5-6) pp. 1001-1016.

Hall, P. (1996). Ciudades del Mañana. Barcelona: Ediciones del Serbal.

Harvey, D. (1989). From managerialism to entrepreneuralism: the transformation in urban governance in late capitalism. Geografiska Annaler (71:1) pp. 3-17.

Huyssen, A. (2002). En busca del futuro perdido. Cultura y memoria en tiempos de globalización. México: Fondo de Cultura Económica.

Judd, D. (2003). El turismo y la geografía de la ciudad. Revista EURE (87) pp. 51-62.

Klein, J. \& Fontan, J.M. (2005). Actor social y gobernanza plural en Montreal: ¿Hacia un nuevo modelo? En C. De Mattos, O. Figueroa, R. Giménez i Capdevilla, A. Orellana \& G. Yáñez (Eds.). Gobernanza, competitividad y redes: la gestión en las ciudades del siglo XXI. Santiago: Instituto de Estudios Urbanos y Territoriales, Pontificia Universidad Católica de Chile.

Marín, L. (2009). De la prepotencia y el habla perdida del curador. Cuadernos de la Escuela de Arte UC (14), pp. 23-37. 
MasterCard Worldwide (2008). Worldwide Centers of Commerce Index. En http://www.mastercard.com/us/company/en/insights/studies/2008/wcoc/index.html

Mellado, J.P. (2008). Bienales: del monumento social a la paradoja identitaria. En www.justopastormellado.cl

Mellado, J.P. (2009). Textos de batalla. Santiago: Metales Pesados.

Montaner, J.M. (2003, 19 de noviembre). La ciudad, ¿̇museo o parque temático? Diario La Vanguardia, Barcelona, culturas pp. 22-23.

Navarro, M. (2009). Mil capas. Cuadernos de la Escuela de Arte UC (14), pp. 69-79.

Pagano, M. \& Bowman, A. (1997). Cityscapes and capital: the politics of urban development. Baltimore: Johns Hopkins University Press.

Rodríguez, A. \& Martínez, E. (2003). Restructuring cities: miracles and mirages in urban revitalization in Bilbao. En F. Moulaert, A. Rodríguez \& E. Swyngedouw (Eds.). The globalized city. Economic restructuring and social polarization in European cities. Oxford: Oxford University Press,

Rogers, R. \& Power, A. (2000). Cities for a small country. Londres: Faber and Faber.

Sassen, S. (1999). La ciudad global. Buenos Aires: EUDEBA.

Sassen, S. (2003). Localizando ciudades en circuitos globales. Revista EURE (88) pp. 5-27.

Sánchez, F. \& Bienenstein, G. (2005). Competitividad, reestructuración urbana y proyectos estratégicos: Camino Niemeyer en Niteroi y Museo Guggenheim en Río de Janeiro. En C. De Mattos, O. Figueroa, R. Giménez i Capdevilla, A. Orellana \& G. Yánez (Eds.). Gobernanza, competitividad y redes: la gestión en las ciudades del siglo XXI. Santiago: Instituto de Estudios Urbanos y Territoriales, Pontificia Universidad Católica de Chile.

Sánchez, J.E. (2005). ¿Qué gobernabilidad? Sistematizar las condiciones de formación metropolitana para abordar las dificultades de comparación de regiones metropolitanas. Reflexión desde Barcelona. En C. De Mattos, O. Figueroa, R. Giménez i Capdevilla, A. Orellana \& G. Yáñez (Eds.). Gobernanza, competitividad y redes: la gestión en las ciudades del siglo XXI. Santiago: Instituto de Estudios Urbanos y Territoriales, Pontificia Universidad Católica de Chile.

Sassen, S. (2007). Una sociología de la globalización. Buenos Aires: Katz Editores.

Smyth, H. (1994). Marketing the city. Londres: E. \& FN Spon.

Vanolo, A. (2008). The image of the creativecity: some reflections on urban branding in Turin. Cities (25) pp. 370-382. 
